\title{
Prevalence of Biofilm Formation and Detection of PSM B Gene in Clinical Isolates of Staphylococcus atrreus
}

Ali Asghar Ayatollahi (MLD) Medical Laboratory Sciences Research Center, Golestan University of Medical Sciences, Gorgan, Iran

Abolfazl Khandan Del (PhD)

Infectious Diseases Research Center, Golestan University of Medical Sciences, Gorgan, Iran

Ailar Jamalli (PhD)

Laboratory Sciences Research Center, Golestan University of Medical Sciences, Gorgan, Iran

Khashayar Shahin (PhD Candidate) Jiangsu Academy of Agricultural Sciences, Nanjing 210014, PR ChinaState Key Laboratory Cultivation Base of MOST, Institute of Food Safety and Nutrition, Jiangsu Academy of Agricultural Sciences, Nanjing 210014, PR China

Ania Ahani Azari (PhD)

Department of Microbiology, Gorgan Branch, Islamic Azad University,

Gorgan, Iran

Tel: +989112750841

Email: ab.khandandel@gmail.com

Corresponding author: Abolfazl Khandan Del

Address: Infectious Diseases Research Center, Golestan University of Medical Sciences, Gorgan, Iran

Received: 21 Sep 2018

Revised: 02 Nov 2019

Accepted: 16 Nov 2019

\section{(c) (i) (8)}

This work is licensed under a Creative Commons Attribution 4.0 License.
ABSTRACT

Background and Objectives: Staphylococcus aureus is a common cause of hospital- and community-acquired infections in the world. This microorganism causes a wide range of diseases, and biofilm formation is as an important mechanism for its virulence. Alpha-toxin and phenol-soluble modulins (PSMs) are among the main factors involved in the biofilm formation by $S$. aureus. The aim of this study was to detect PSM B gene among biofilm-forming $S$. aureus clinical isolates from hospitalized patients at the $5^{\text {th }}$ Azar Hospital in Gorgan, Iran.

Methods: Clinical specimens were collected and examined for presence of $S$. aureus using conventional microbiological and biochemical tests. Then, biofilm formation ability of S. aureus isolates was evaluated using the microtiter plate assay. In addition, presence of the PSM B gene was assessed using real-time PCR.

Results: 0 1,800 clinical isolates, $60(3.3 \%)$ were identified as $S$. aureus. 0 these isolates, 47 (78.3\%) were positive for biofilm formation. The PSM $B$ gene was present in all biofilm-forming isolates. Results of the phenotypic and genotypic biofilm tests were closely linked and the rate of PSM B expression was $80 \%$.

Conclusion: The prevalence of biofilm-producing $S$. aureus clinical isolates from patients hospitalized in the $5^{\text {th }}$ Azar hospital of Gorgan (Iran) is relatively high, which could pose a serious challenge. Therefore, regular surveillance of biofilm formation in $S$. aureus isolates and their antimicrobial resistance profiles is highly recommended.

Keywords: PSM B gene, clinical isolates, Staphylococcus aureus, biofilms.

This paper should be cited as: Ayatollahi AA, Khandan Del A, Jamalli A, Shahin KH, Ahani Azari A [Prevalence of Biofilm Formation and Detection of PSM B Gene in Clinical Isolates of Staphylococcus aureus]. mljgoums. 2020; 


\section{INTRODUCTION}

Staphylococcus aureus is a common human pathogen that has been considered as the main cause of hospital-acquired infections in the world (1). It causes a wide range of infections, including bacteremia, septicemia and pneumonia, as well as skin, soft tissue and bone infections (2). Respiratory tract infections accounts for majority of the hospital-associated $S$. aureus infections, while skin and soft tissue infections are dominant among community-associated $S$. aureus infections (3). This microorganism has many virulence factors among which biofilm formation is of upmost importance for development of resistance to antimicrobial agents, making it a major problem for hospitalized patients and medical staff (4). Infections caused by biofilm-producing $S$. aureus increase the length of hospital stay and are associated with more clinically important infections such as pneumonia, polyarthritis, necrotizing fasciitis, endocarditis and septicemia (5). Alpha-toxin and phenolsoluble modulins (PSMs) including PSM A and PSM B that are encoded on the core genome of $S$. aureus, have an extensive range of functional activities, such as supporting biofilm formation during $S$. aureus infections (6). Since biofilm formation is a key factor for survival and resistance of $S$. aureus strains, monitoring the prevalence of biofilmproducing $S$. aureus and identification of genes involved in the process are essential, especially in clinical isolates. Therefore, the aim of this study was to detect the PSM B gene among biofilm-forming $S$. aureus clinical isolates.

\section{MATERIALS AND METHODS}

The study received approval from the Golestan University of Medical Sciences, Iran (ethical

approval

code:

IR.GOUMS.REC.1397.116). Samples were collected from different wards of the $5^{\text {th }}$ Azar Hospital in Gorgan, Iran. The samples were examined for $S$. aureus using conventional biochemical and bacteriological tests such as culture on manitol salt agar, gram staining, catalase, oxidase, coagulase and DNase tests (7).

The biofilm formation ability was evaluated by microtiter plate assay. For this purpose, a 24hour culture of each bacterial isolate was inoculated in Mueller Hinton agar and TSB medium containing $1 \%$ glucose and incubated at $37{ }^{\circ} \mathrm{C}$. When the opacity of the tubes reached 0.5 McFarland standard $(0.08 \%$ $0.13 \%$ absorbance at $625 \mathrm{~nm}$ ), $200 \mu \mathrm{l}$ of the bacterial suspension were inoculated into wells of a 96-well microplate. In addition, TSB medium with $1 \%$ glucose and $S$. aureus 35556 were used as the negative and positive control, respectively (8). To visualize biofilms, each well was treated with $200 \mu \mathrm{l}$ of $2 \%$ crystalline violet for 5 minutes. The excess stain was discarded and the wells were washed with phosphate buffer saline three times. Next, 200 $\mu \mathrm{l}$ of ethanol-acetone (20-80\%) were added to each well to remove the crystals from the bacteria and biofilms. After 30 minutes, absorbance of each well was measured at 570 $\mathrm{nm}$ using an ELISA reader. A semiquantitative analysis of biofilm formation using cut-off calculations was carried out in accordance with the following formula: mean optical density of negative controls + three times the standard deviation was considered as a cut-off point $(9,10)$. The absorbance of each isolate was measured three times. The method for calculating the quotient amount for each group and interpretation of results is presented in Table 1 and Figure 1.

Table 1- Classification of $S$. aureus clinical isolates based on their biofilm-forming ability using the microtiter plate assay

\begin{tabular}{ccc}
\hline Mean OD & Cut-off value & Biofilm-forming ability \\
\hline OD $>1.2$ & OD $>$ 4 $\times$ ODc 2 & Strong \\
$0.7<$ OD $\leq 1.2$ & $2 \times$ ODc $<$ OD $\leq 4 \times$ OD & Moderate \\
$0.3<$ OD $\leq 0.6$ & ODc $<$ OD $\leq \mathbf{2} \times$ ODc & Weak \\
OD $\leq \mathbf{0 . 3}$ & OD $>$ cut off & None \\
\hline
\end{tabular}

Cut off $=$ average OD of negative control $+(3 \times$ standard deviation of negative control $)$ 
Figure 1- Biofilm formation based on the microtiter plate assay

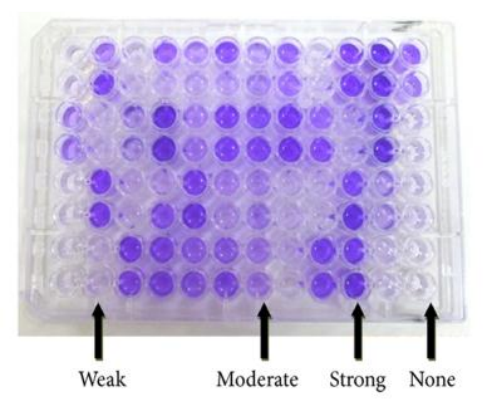

Table 2- Sequence of the primers used for the amplification of PSM B

\begin{tabular}{cccc}
\hline Name & Sequence $(5 \quad 3)$ & $\begin{array}{c}\text { Product size } \\
(\text { bp })\end{array}$ & Reference \\
\hline$P S M B(F)$ & TAATAATGACGGCGCAAAATTAGG & 238 & $(20)$ \\
$P S M B(R)$ & GCAACGATGTCTACGATACTTGTGC & & \\
\hline
\end{tabular}

Table 3- Preparation of the reaction mixture for real-time PCR

\begin{tabular}{ccc}
\hline Component & Volume/reaction & Final Concentration \\
\hline 2x QuantiFast SYBR Green Master Mix & $12.5 \mu \mathrm{l}$ & $1 \mathrm{x}$ \\
Primer F & $1 \mu \mathrm{l}$ & $1 \mu \mathrm{M}$ \\
Primer R & $1 \mu \mathrm{ll}$ & $1 \mu \mathrm{M}$ \\
cDNA template & $4 \mu \mathrm{l}$ & $5 \mathrm{ng}(1-10 \mathrm{ng})$ \\
RNase-free water & $6.5 \mu \mathrm{l}$ & - \\
Total reaction volume & $25 \mu \mathrm{l}$ & - \\
\hline
\end{tabular}

Table 4-Cycling conditions for the real-time PCR

\begin{tabular}{ccc}
\hline Step & Time & Temperature \\
\hline PCR initial activations & 15 min & $5^{\circ} \mathrm{C}$ \\
Denaturation & $15 \mathrm{~s}$ & $9^{\circ} \mathrm{C}$ \\
Combined & $60 \mathrm{~s}$ & $\mathbf{6 0}^{\circ} \mathrm{C}$ \\
annealing/extention & & \\
Number of cycles & & 35 \\
\hline
\end{tabular}

RNA was extracted from the biofilmproducing $S$. aureus isolates using the RNXPlus kit (CinaGene Co., Iran) as described previously (11). Quality and quantity of the extracted RNA was evaluated by electrophoresis on $1.2 \%$ agarose gel and spectrophotometry, respectively.

The amount of gene expression in the extracted RNA was determined by real-time PCR (ABI Prism 7300 Applied Biosystems). Table 2 shows the sequence of the primers used for gene expression analysis. Genomic amplification was performed using QuantiFast SYBR Green Master Mix (Qiagen, Hilden, Germany) as described in Table 3. The cycling conditions are displayed in table 4.Descriptive quantitative variables were computed by calculating central indexes, dispersion and plotting. Qualitative variables were computed by calculating the frequency percentage. All statistical analyses were performed in SPSS 16 using ANOVA and chi-square tests. A p-value of less than 0.05 was considered as statistically significant. 


\section{RESULTS}

Of 1,800 clinical isolates, 60 isolates (3.3\%) were identified as $S$. aureus. Of these isolates, $27(47 \%)$ were isolated from men and $33(53 \%)$ were isolated from women. The mean age of patients with $S$. aureus bacteremia was 37.8 years and the highest rate $(40 \%)$ of $S$. aureus carriers was observed in patients aged 15-25 years. There was no statistically significant correlation between the mean age of patients and $S$. aureus infection $(\mathrm{P}=0.03)$.

Of the $60 \mathrm{~S}$. aureus clinical isolates, 47 (78.3\%) were positive for biofilm formation. The biofilm-forming strains were isolated from urine $(n=12)$, blood $(n=5)$, cerebrospinal fluid $(n=8)$, wound $(n=17)$ and abscess $(n=5)$ specimens. Based on the results of the microtiter plate assay, $30(50 \%)$ isolates were strong biofilm producer, $17(28.3 \%)$ isolates were weak biofilm producer and $13(21.7 \%)$ isolates were non-biofilm producer. No obvious correlation was found between specimen source, gender of patients and the biofilm formation ability $(\mathrm{P}>0.05)$.

Based on the results of the real-time PCR experiment, all 47 biofilm-producing isolates were positive for the PSM B gene. Moreover, results of the phenotypic and genotypic characterization of biofilm formation were closely related to each other and the rate of PSM B expression was $80 \%$.

\section{DISCUSSION}

As a common cause of hospital- and community-acquired infections, biofilmproducing and resistant $S$. aureus strains are of great clinical importance. Biofilm formation helps bacteria adhere to tissues or medical indwelling devices, which could potentially cause life-threatening infections. Alpha-toxin and PSMs are involved in biofilm formation by $S$. aureus strains (12). Recently, concerns have been raised about the survival and resistance of biofilm-forming strains. As a result, monitoring the prevalence of biofilmproducing $S$. aureus and identification of genes involved in the process are essential, particularly in clinical isolates (13).

In two previous studies, more than $85 \%$ of $S$. aureus clinical isolates were able to form biofilm $(14,15)$. In a study conducted by Christensen et al., $48.5 \%$ of clinical isolates were able to produce biofilm (16). Cafiso et al. reported that $57.5 \%$ of isolates from in-patient medical equipment were biofilm producer
(17). In the present study, the prevalence of strong, weak and non-biofilm producing isolates was $50 \%, 28.3 \%$ and $21.7 \%$, respectively. In another study in Iran, $68 \%$ of clinical isolates from a hospital were strong biofilm producer (18). Consistent with the result of our study, the prevalence of biofilmproducing $S$. aureus isolates from hospital infections in Shahrekord (the capital city of Chaharmahal and Bakhtiari Province, Iran) was $86 \%$ (19). Namvar et al. detected the intercellular adhesion gene cluster (ica) in $S$. aureus clinical isolates and reported the prevalence of biofilm-producing isolates to be $58 \%$ in the quantitative biofilm assay (20). In our study, 47 (78.3\%) isolates were identified as biofilm-producing strains. Moreover, all 47 biofilm-forming isolates contained the PSM $B$ gene. In a study by Fursova et al., the PSM B gene was present in $95 \%$ of the isolates (21). Given that biofilm formation is associated with development of antimicrobial resistance, detection of the genes involved in the biofilm formation process and regular monitoring of biofilm formation by clinically important bacteria such as $S$. aureus may contribute to early treatment of infections.

\section{CONCLUSIONS}

The prevalence of biofilm-producing $S$. aureus clinical isolates from hospitalized patients in the $5^{\text {th }}$ Azar hospital of Gorgan (Iran) is relatively high, which could pose a serious challenge. Therefore, regular surveillance of biofilm formation in S. aureus isolates and their antimicrobial resistance profiles is highly recommended. It is also crucial to disinfect and sterilize surfaces and medical equipment in the hospital setting to minimize the risk of contamination and spread of bacteria.

\section{ACKNOWLEDGMENTS}

This project (approval code: 110152) was financially supported by the Infectious Disease Research Center of Golestan University of Medical Sciences, Iran. The authors would like to thank all colleagues at the Gorgan Medical School for their contribution in lab work.

\section{CONFLICT OF INTEREST}

The authors declare that there is no conflict of interest. 


\section{REFERENCES}

1. Ruiz A, Mora M, Zurita C, Larco D, Toapanta Y, Zurita J. Prevalence of methicillin-resistant Staphylococcus aureus among health care workers of intensive care units in Ecuador. J Infect Dev Ctries.. 2014; 8(01): 116-9.

2. Secchi C, Antunes ALS, Perez LRR, Cantarelli VV, $\mathrm{d}$ 'Azevedo PA. Identification and detection of methicillin resistance in non-epidermidis coagulase-negative staphylococci. Braz J Infect Dis. 2008; 12(4): 316-20.

3. DeLeo FR, Otto M, Kreiswirth BN, Chambers HF. Community-associated meticillin-resistant Staphylococcus aureus. The Lancet. 2010; 375(9725): 1557-68.

4. Piette A, Verschraegen G. Role of coagulase-negative staphylococci in human disease. Vet Microbiol. 2009; 134(1-2): 45-54. doi: 10.1016/j.vetmic.2008.09.009.

5. DeLeo FR, Otto M. An antidote for Staphylococcus aureus pneumonia? J Exp Med. 2008; 205(2): 271-4. doi: 10.1084/jem.20080167.

6. Periasamy S, Joo H-S, Duong AC, Bach T-HL, Tan VY, Chatterjee SS, et al. How Staphylococcus aureus biofilms develop their characteristic structure. Proc Natl Acad Sci U S A. 2012; 109(4): 1281-6. doi: 10.1073/pnas.1115006109.

7. Croes S, Deurenberg RH, Boumans M-LL, Beisser PS, Neef C, Stobberingh EE. Staphylococcus aureus biofilm formation at the physiologic glucose concentration depends on the S. aureus lineage. BMC Microbiol. 2009; 9: 229. doi: 10.1186/1471-2180-9-229.

8. Wang R, Braughton KR, Kretschmer D, Bach T-HL, Queck SY, Li M, et al. Identification of novel cytolytic peptides as key virulence determinants for communityassociated MRSA. Nature medicine. 2007; 13(12): 1510.

9. Rautenberg M, Joo H-S, Otto M, Peschel A. Neutrophil responses to staphylococcal pathogens and commensals via the formyl peptide receptor 2 relates to phenol-soluble modulin release and virulence. FASEB J. 2011; 25(4): 1254-63.

10. Cheung GY, Rigby K, Wang R, Queck SY, Braughton KR, Whitney AR, et al. Staphylococcus epidermidis strategies to avoid killing by human neutrophils. PLoS pathogens. 2010; 6(10): e1001133.

11. Khandan Del A, Kaboosi H, Jamalli A, Peyravii Ghadikolaii F. Prevalence and Expression of PSM A Gene in Biofilm-Producing Staphylococcus aureus Clinical Isolates. Jundishapur J Microbiol. 2019 August; 12(8):e89610.

12. Kretschmer D, Gleske A-K, Rautenberg M, Wang R, Köberle M, Bohn E, et al. Human formyl peptide receptor 2 senses highly pathogenic Staphylococcus aureus. Cell Host Microbe. 2010; 7(6): 463-73.
13. Wallecha A, Oreh H, van der Woude MW, deHaseth PL. Control of Gene Expression at a Bacterial Leader RNA, the agn43 Gene Encoding Outer Membrane Protein Ag43 of Escherichia coli. J. Bacteriol. 2014; 196(15): 2728-35

14. Cucarella C, Tormo MÁ, Knecht E, Amorena B, Lasa I, Foster TJ, et al. Expression of the biofilm-associated protein interferes with host protein receptors of Staphylococcus aureus and alters the infective process. Infect Immun. 2002; 70(6): 3180-6.

15. Arya M, Shergill IS, Williamson M, Gommersall L, Arya N, et al. Basic principles of real-time quantitative PCR. Expert Rev Mol Diagn. 2005; 5(2): 209-19.

16. Christensen GD, Simpson W, Younger J, Baddour L, Barrett F, Melton D, et al. Adherence of coagulasenegative staphylococci to plastic tissue culture plates: a quantitative model for the adherence of staphylococci to medical devices. J Clin Microbiol. 1985; 22(6): 9961006.

17. Cafiso V, Bertuccio T, Santagati M, Demelio V, Spina D, Nicoletti G, et al. Agr-Genotyping and transcriptional analysis of biofilm-producing Staphylococcus aureus. FEMS Immunology \& Medical Microbiology. 2007; 51(1): 220-7.

18. Eftekhar F, Dadaei T. Biofilm formation and detection of icaAB genes in clinical isolates of methicillin resistant Staphylococcus aureus. Iranian Journal of basic medical sciences. 2011; 14(2): 132-6.

19. Nourbakhsh F, Momtaz H. Evaluation of Phenotypic and Genotypic Biofilm Formation in Staphylococcus aureus Isolates Isolated from Hospital Infections in Shahrekord, 2015. J Arak Uni Med Sci. 2016; 19(4): 6979.

20. Namvar AE, Asghari B, Ezzatifar F, Azizi G, Lari AR. Detection of the intercellular adhesion gene cluster (ica) in clinical Staphylococcus aureus isolates. GMS Hyg Infect Control. 2013; 8(1): Doc03. doi: 10.3205/dgkh000203.

21. Fursova K, Shchannikova M, Loskutova I, Shepelyakovskaya A, Laman A, Boutanaev A, et al. Exotoxin diversity of Staphylococcus aureus isolated from milk of cows with subclinical mastitis in Central Russia. J Dairy Sci. 2018; 101(5): 4325-4331. doi: 10.3168/jds.2017-14074. 